\title{
IN DISCIPLINA E VIOLÊNCIA NAS ESCOLAS: algumas questões a considerar
}

\author{
Indiscipline and violence in schools: \\ some issues to consider
}

\begin{abstract}
Joe Garcia
D outor em Educação pela Pontifícia Universidade Católica de São Paulo (PUC-SP), Professor do Programa de Pós-Graduação em Educação da Universidade Tuiuti do Paraná (UTP), Curitiba, PR - Brasil, e-mail: joe@ sul.com.br
\end{abstract}

\begin{abstract}
Resumo
Este artigo apresenta uma análise de pesquisa no campo dos estudos sobre indisciplina e violência nas escolas, propondo alguns avanços nos processos de gestão educacional, tendo por base um conjunto de leituras teóricas e observações realizadas em um conjunto de escolas de Educação Básica, ao longo dos últimos cinco anos. Argumentamos que os problemas de indisciplina e violência solicitam uma profunda revisão em nossas visões e práticas pedagógicas, uma mudança de paradigma em termos de gestão educacional, pois colocam em questão o próprio projeto educacional, e portanto as finalidades mais amplas do ato educacional, e não somente as iniciativas e práticas dos professores. 0 texto desenvolve uma análise em três momentos. Inicialmente exploramos um conjunto de questões sobre indisciplina e violência nas escolas, tendo por referências estudos realizados por
\end{abstract}

Rev. Diálogo Educ., Curitiba, v. 9, n. 28, p. 511-523, set./ dez. 2009 
diferentes pesquisadores. Em seguida, argumentamos sobre a necessidade de avançar na direção de um novo paradigma na gestão educacional, em relação às questões de indisciplina e violência nas escolas. A seguir, tendo por base um conjunto de observações realizadas em um grupo de escolas, exploramos um conjunto de aspectos a serem transformados, relativos à perspectiva de mudança nos processos de gestão educacional, tendo em mente efetuar avanços no enfrentamento dos problemas relacionados à indisciplina e violência. Na última parte apresentamos um conjunto de considerações finais, destacando a importância da escola redesenhar processos de formação e priorizar ações pró-ativas baseadas no desenvolvimento de visões compartilhadas, como forma de superar fragmentações usuais nas ações relacionadas a indisciplina e violência nas escolas.

Palavras-chave: Educação. Indisciplina. Violência. Mudança de paradigma.

\begin{abstract}
This article presents a research analysis related to indiscipline and school violence studies, proposing some advances in the processes of educational management, based on theoretical readings and field observations carried through in a set of schools, throughout the last five years. We argue that the problems of indiscipline and violence request a deep revision in our pedagogical views and practices, a change of paradigm in terms of educational management, because those challenge the educational project itself, and therefore the broadest purposes of the educational act, and not only the initiatives and practical of the teachers. The text develops an analysis at three levels. Initially we explore a set of questions about indiscipline and violence in the schools, having for references studies carried through for different researchers. After that we argue about the necessity to advance in the direction of a new paradigm in the educational management, in relation to the issues of indiscipline and violence in the schools. Then, having for base a set of observations carried through in a group of schools, we explore a set of aspects to be transformed in the educational management, having in mind to produce advances
\end{abstract}

Rev. Diálogo Educ., Curitiba, v. 9, n. 28, p. 511-523, set./ dez. 2009 
in dealing with problems related to indiscipline and violence. In the last part we present a set of final thoughts about the importance of redesigning teachers education and putting priority in proactive actions, based in shared views, as a way of going beyond the fragmentation in the actions related the indiscipline and violence in the schools.

Keywords: Education. Indiscipline. School violence. Paradigm changing.

\section{INTRODUÇÃO}

Nas últimas décadas as questões de indisciplina e violência nas escolas passaram a se destacar entre as principais preocupações dos educadores, particularmente nos países industrializados (DEBARBIEUX, 2002, 2007; ESTRELA, 2002; FURLAN, 1998; G O RD O N, 1999). Tais problemas vêm afetando o ambiente escolar, 0 currículo e as relações interpessoais em sala de aula, e apresentam diversos desafios a serem superados, einterrogações a serem investigadas.

A literatura educacional contemporânea apresenta uma diversidade de leituras teóricas sobre indisciplina e violência nas escolas. Nos escritos de pesquisadores brasileiros, embora não possamos discernir um debate acadêmico articulado ao redor de interrogações comuns, observa-se, entretanto, a noção de que tais problemas seriam uma fonte principal de preocupação entre professores de Educação Básica, que percebem com preocupação algumas mudanças no ambiente educativo das escolas (ABRAMOVAY ; RUA, 2004; AQ UINO , 1996; D 'ANTO LA, 1989; FRELLER, 2001; REBELO, 2002).

Neste artigo analisamos indisciplina e violência como forças que atuam sobre as práticas pedagógicas das escolas, sendo capazes de afetar não somente as iniciativas e práticas dos professores, mas 0 cumprimento das finalidades mais amplas que se deseja atingir naquele espaço, em termos de aprendizagem, socialização, acesso à cultura e formação para a cidadania. Nesse sentido, argumentamos que indisciplina e violência representam problemas a serem pensados sob a perspectiva ampla dos processos de gestão escolar.

Essaformadeleiturarefleteumainterrogação quetemos observado estar presente entre muitos educadores, preocupados com o modo como

Rev. Diálogo Educ., Curitiba, v. 9, n. 28, p. 511-523, set./ dez. 2009 
os problemas de indisciplina e violência têm se ampliado nas escolas, e com as implicações que estes projetam sobre as práticas pedagógicas. Diante desses problemas, a escola, afinal, consegue cumprir efetivamente seu papel educativo? A percepção de uma escola interrompida, em função de indisciplina e violência, nos instiga a investigar tanto aqueles aspectos em crisequanto aquilo quepoderiasertransformado tendo em vistaanecessidade de superação dos desafios representados por aqueles problemas.

Alguns teóricos têm afirmado que indisciplina e violência afetam a qualidade do processo de ensino-aprendizagem, 0 desdobramento do currículo, e podem transtornar nossas melhores visões e práticas educacionais (AMADO, 2001; ARUM, 2005; D 'ANTOLA, 1989; XAVIER, 2002). Os problemas de indisciplina e violência, portanto, representam forças que atuam em diversasinstâncias do trabalho e projeto educacional das escolas.

Mas existe uma outra leitura a realizar em relação às questões de indisciplina e violência nas escolas. Ao mesmo tempo em que podem ser pensadas como forças de resistência e fragmentação do projeto educativo, também podem ser interpretadas como elementos de uma crise a solicitar transformações em relação ao que estamos pensando e praticando nas escolas - e de modo maios amplo na sociedade, se desejarmos ampliar nossa análise.

Segundo a leitura acima, indisciplina e violência representam uma tensão de mudança que solicitam das escolas que aprendam a conjugar de um modo diferente 0 potencial dos atores, recursos e ambientes que ali se apresentam, e a desdobrar novas visões, estratégias efinalidades da própria E ducação. Nesse sentido, poderíamos questionar, por exemplo, se nossas escolas estão comprometidas com uma cultura da paz. Estamos, em nossas escolas, cultivando as visões necessárias para enfrentar os principais desafios na nossa época? O currículo, afinal, está contextualizado e pode ser considerado significativo? Em sala de aula, estamos explorando as questões queatravessam sociedade contemporânea?

A perspectiva aqui apresentada reflete uma percepção de que as expressões de indisciplina e violência representam desafios que solicitam uma mudança de paradigma, e não somente um conjunto de ações parciais que muitas vezes afetam a escola de tal forma a fragmentar seu papel social mais amplo. Portanto, tendo em mente explorar 0 horizonte sugerido acima, neste artigo apresentamos um conjunto de análises sobre indisciplina e violência nas escolas, baseadas em leituras teóricas e em observações realizadas em um conjunto de instituições de Educação Básica, ao longo dos últimos cinco anos. Em função de

Rev. Diálogo Educ., Curitiba, v. 9, n. 28, p. 511-523, set./ dez. 2009 
diversos trabalhos desenvolvidos junto a tais instituições, pudemos sistematizar observações ao redor de um conjunto de desafios fundamentais a serem enfrentados pelos educadores, no trabalho relativo à indisciplina nas escolas em termos de gestão educacional.

Este texto está organizado em três seções. Inicialmente refletimos sobre um conjunto de questões sobre indisciplina e violência nas escolas. Em seguida argumentamos quanto à necessidade de uma mudança de paradigma na gestão educacional. Na última parte apresentamos um conjunto de considerações finais, destacando algumas análises desdobradas neste trabalho.

\section{Indisciplina e violência nas escolas}

Há vários desafios no horizonte das escolas na atualidade. Alguns são mais recentes e se revelaram, por exemplo, com a implementação da reforma educacional que estamos realizando em nosso país. O utros são mais antigos, persistentes e complexos. Este é 0 caso dos problemas de indisciplina e violência nas escolas.

As expressões de indisciplina e violência vêm há muito tempo produzindo diversos tipos de mal-estar nas escolas. Incidentes de indisciplina e violência têm sido reportados e investigados em diversos países, a ponto de serem considerados uma preocupação mundial (ABRAMOVAY; RUA, 2004; D EBARBIEUX , 2007; ESTRELA , 2002). São fontes antigas de dilemas, mas também capazes de solicitar dos educadores novas visões, teorias e práticas educacionais.

Nas últimas décadas, particularmente em instituições de educação básica, tem se delineado uma tendênciade diversificação eintensificação das expressões deindisciplina eviolência(ABRAMOVAY;RUA, 2004;ARUM, 2005; G O RD ON , 1999). Além disso, tais fenômenos estariam avançando em complexidade, como se estivesse em curso algum tipo de "evolução" em suas expressões. Argumentamos, entretanto, que esse cenário precisa ser analisado não somente como um indicativo de problemas, mas particularmente como uma solicitação por transformações nas escolas.

Os problemas de indisciplina e violência nas escolas podem ser relacionados a uma crise em relação à segurança e respeito no ambiente escolar. Também dedestacaa preocupação com aautoridadedos professores em sala de aula. $\mathrm{O}$ fundamento da autoridade tradicional dos professores, em sala deaula, residiriaem seu estatuto intelectual ecompetênciaprofissional para ensinar, os quais poderiam lhe conferir distinção e uma posição

Rev. Diálogo Educ., Curitiba, v. 9, n. 28, p. 511-523, set./ dez. 2009 
hierárquica superior em relação aos alunos. Mais recentemente, o processo delegitimação da autoridade dos professores passa a destacar o modo como estes interagem com os alunos. Assim, para exercer uma autoridade legítima, os professores precisam demonstrar uma competência para ensinar, bem como competência interpessoal em sala de aula.

$\mathrm{Na}$ atualidade, ainda persiste, entre muitos educadores, a ideia de disciplina como algo que solicita processos de controle e punição, tendo em vista garantir a manutenção de um determinado estado de ordem. Ainda persiste a noção de que disciplina, por exemplo, é algo construído a partir do fortalecimento unilateral da autoridade dos professores, dos pais e das instituições de ensino, e do endurecimento das consequências dos atos considerados indisciplinados.

Mas a tensão causada pela incidência desses problemas nas escolas tem sido acompanhada, particularmente nas últimas duas décadas, de um conjunto de pesquisas e iniciativas, particularmente em países industrializados, e novas perspectivas teóricas e práticas so ciais têm sido produzidas para lidar com tais problemas. Recentemente, os cenários de indisciplina e violência passaram a ser analisados segundo leituras sociológicas mais amplas (ARUM, 2005; DEBARBIEUX; BLAYA, 2002). Na escola, diversas análises buscam situar aqueles problemas ao contexto complexo das relações entre as diversas forças, atores sociais e aspectos que compõe a escola (AMAD 0 , 2001).

Mas as questões de indisciplina eviolência precisam ser pensadas no horizonte mais amplo do que entendemos por escola e sua finalidade social. Algumas alternativas que têm sido propostas para o enfrentamento desses problemas destacam a necessidade não somente de inserir práticas pontuais, mas de transformar racionalidades. Portanto, se desejamos transformar os quadros de indisciplina e violência nas escolas, será necessário repensar conceitos, modelos e práticas sociais que ali têm sido exercidos. É nesse sentido que nos parece importante pensar nesse avanço como uma mudança de paradigma.

\section{A perspectiva de uma mudança de paradigma}

O termo paradigma se tornou bastante usual na literatura educacional nas últimas décadas. É um conceito importante que remete ao tecido subjacente às teorias, práticas, valores evisões compartilhadas de uma comunidade científica (KUHN, 1977). A noção de mudança de paradigma se refere a uma transformação profunda em um grupo social.

Rev. Diálogo Educ., Curitiba, v. 9, n. 28, p. 511-523, set./ dez. 2009 
No processo de transição, a crise desempenha um papel fundamental. Ela é indicativo que as teorias e práticas dentro de uma comunidade, por exemplo, já não conseguem fornecer respostas satisfatórias a questões importantes. Assim, as visões até então dominantes entram em crise, e novas respostas vão buscadas em outras fontes.

Nas escolas é possível observar a utilização de estratégias de enfrentamento dos problemas de indisciplina e violência, baseadas em lógicas de regulação social e repressão, pedagogicamente pouco efetivas e inconsistentes. Assim, a crítica principal a ser feita, neste cenário, deve estar voltada não somente aos procedimentos, mas sobretudo às racionalidades subjacentes às ações empreendidas nas escolas. Aqui argumentamos que as racionalidades em curso já não respondem aos desafios colocados às escolas. Nesse sentido, os cenários de indisciplina e violência nas escolas representam uma crise a indicar a necessidade de uma mudança de paradigma.

As expressões de indisciplina e violência nas escolas revelam a necessidade de uma profunda revisão em nossas teorias e práticas relacionadas a diversas questões. D e um lado isso requer investigação. Entretanto, em algum momento será fundamental uma disposição para implementar novas visões, teorias e práticas. Assim, embora a urgência de desenvolver novas práticas pedagógicas diante das expressões de indisciplina e violência nas escolas, seria prioritário elaborar novas concepções que fundamentem tais ações, tendo em vista as circunstâncias e dilemas atuais com os quais as escolas estão lidando.

Em meio a esse cenário, parece sobressair a necessidade de repensar e avançar, de um modo abrangente, pressupostos e formas de ação. De fato, o que se coloca é a necessidade de uma mudança de paradigma. Q uando nos referimos a uma mudança de paradigma, temos em mente a importância de modificarmos as respostas básicas que têm sido dadas a perguntas fundamentais enunciadas por educadores há séculos, tais como: O que é indisciplina? O que é violência? Q uais suas causas, sentidos eimplicações?Q ueações empreender?Para essasmesmas 'velhas' perguntas, precisamos tecer respostas novas, que sejam capazes de sugerir diferentes linhas de ação pedagógica, capazes de transformar cenários na escola, e originar soluções segundo novas perspectivas educacionais.

Sob a perspectiva acima, certas ações que têm sido recorrentes nas escolas, nos parecem pouco efetivas. Como exemplo, podemos destacar a tendência usual de investir isoladamente na capacitação dos professores, pressupondo que em suas mãos reside o eixo da solução dos problemas de indisciplina e violência na escola. A formação de

Rev. Diálogo Educ., Curitiba, v. 9, n. 28, p. 511-523, set./ dez. 2009 
professores é algo necessário para implementar uma reforma educativa e produzir inovação pedagógica na escola (NÓVOA, 1995, p. 9). Entretanto, é preciso atenção às lógicas que estarão atravessando os processos formativos, bem como as finalidades desejadas.

Argumentamos que a formação precisa estar atenta, por exemplo, a uma perspectiva de enfrentamento dos problemas de indisciplina e violência que enfatize particularmente a dimensão próativa das práticas educacionais. A lém disso, nos parece necessário superar a influência de abordagens comportamentalistas e 0 viés das estratégias comprometidas com mecanismos de controle e punição.

Um reflexo comum da persistência e sobrevivência prolongada desse tipo de abordagem nas escolas reside na ênfase usualmente colocada em procedimentos de intervenção, que apostam em soluções dirigidas por elementos externos aos próprios esforços dos estudantes, seja na forma de agentes e mecanismos de vigilância e controle da conduta, de ações punitivas pedagogicamente questionáveis e pouco efetivas, ou mesmo de soluções que exploram processos de premiação, abertos ou velados - que po dem reproduzir formas sutis de diferenciação social, ou mesmo afetar o desenvolvimento da autonomia dos estudantes.

A propósito das estratégias de enfrentamento da violência nas escolas, há um risco de nos mantermos limitados a enfoques repressivos, ou imobilizados por concepções que afirmam aos educadores a impossibilidade da escola agir de um modo efetivamente transformador. Neste cenário, é importante destacar iniciativas tais como os programas de educação para a paz, voltados ao engajamento consciente dos diversos atores que compõe a comunidade escolar.

Tendo em vista a necessidade de transformar o tecido mais amplo e complexo que sustenta e orienta as decisões e ações so bre o que se vai fazer antes e diante do cenário de indisciplina e violência nas escolas, afirmamos a necessidade de exercermos formas mais amplas de compreensão e ação social. Mas tais mudanças de perspectiva precisam estar refletidas nas visões e práticas de gestão educacional. Na seção a seguir exploramos essa questão.

\section{Mudando perspectivas de gestão educacional}

Nesta seção, a partir das questões analisadas anteriormente, e com base em observações realizadas em instituições de educação básica, exploramos um conjunto de aspectos a serem transformados, relativos

Rev. Diálogo Educ., Curitiba, v. 9, n. 28, p. 511-523, set./ dez. 2009 
à perspectiva de mudança nos processos de gestão educacional, tendo em mente efetuar avancos no enfrentamento dos problemas relacionados à indisciplina e violência. Nesse sentido, argumentamos quanto importância de buscar-se uma mudança de paradigma, no sentido proposto por Kuhn (1977).

A complexidade que hoje assumem as expressões de indisciplina e violência nas escolas parece requerer uma perspectiva de gestão derivada de uma forma de diálogo entre os diversos atores da comunidade escolar, capaz de produzir uma visão compartilhada, que alimente e direcione esforços coletivos e oriente um conjunto de práticas a serem exercidas na escola. Mas porque investir na construção de uma visão compartilhada na escola? Em que medida isso representa um avanço em termos de gestão educacional das questões de indisciplina e violência nas escolas?

Nos últimos cinco anos pudemos observar os modos de enfrentamento das questões de indisciplina e violência em um grupo de instituições de educação básica. Constatamos, por exemplo, aimportância de cultivar o que se pode denominar de visão compartilhada, como um elemento fundamental para a gestão educacional de diversos aspectos na escola, inclusive as questões de indisciplina e violência. A existência de uma visão compartilhada torna possível e veicula um nível de articulação, entendimento e conjugação realmente capazes de fazer a diferença nas práticas educacionais.

E sta visão compartilhada refere-se a uma forma de perspectiva socialmente construída, composta de princípios, orientações e atribuições. É uma espécie de tecido que passa a revestir as ações empreendidas na escola, nos enfrentamentos dos problemas de indisciplina e violência. A ausência desse tecido pode fragilizar projetos de transformação, multiplicando divergências e descontinuidades, e abrir espaços para o esvaziamento das iniciativas empreendidas.

Um outro aspecto a destacar reside no avanço necessário em direção a práticas preventivas, que devem assumir um papel de predominância nas escolas. Essa noção derivou de observações realizadas a propósito do modo como as escolas observadas desenhavam os projetos de formação continuada dos seus educadores. Lidar com indisciplina e violência na atualidade requer um trabalho baseado em novas competências profissionais. Mas se os educadores precisam exercer novas forma de relacionamento e liderança no ambiente escolar, por exemplo, também precisam atuar mais segundo um senso pedagógico coletivo, contextualizado pelo projeto pedagógico das instituições onde atuam.

Rev. Diálogo Educ., Curitiba, v. 9, n. 28, p. 511-523, set./ dez. 2009 
A través daformação torna-semais viável pensarno deslocamento das práticas pedagógicas tradicionalmente de base interventiva, e repressivas, em direção a práticas pró-ativas. Em outros termos, os trajetos de formação precisam voltar-se ao desenvolvimento de competências profissionais que permitam aos educadores atuar sobretudo segundo linhas de ação pró-ativa, através das quais possam trabalhar 0 engajamento dos estudantes aos processos de ensino-aprendizagem, avançar a qualidade do currículo e portanto no desenho de experiências formativas atentas a necessidades de investir no desenvolvimento de recursos internos, que se reflitam na habilidade para resolver conflitos ou em atitudes que sustentem uma cultura de paz nas escolas.

Um terceiro aspecto destacado das observações que realizamos, refere-se à relação entre escola e família. Argumentamos que as escolas também precisam de um novo paradigma de gestão educacional no que se refere à relação com a família. Essa relação, embora em teoria seja destacada evalorizada pelas duas partes, na prática comumente apresenta diversos limites. Tais limites resultam de diversos aspectos, tais como 0 baixo nível de engajamento dos pais, ou da própria forma como as escolas assumem posições pouco democráticas ao estabelecerem a si mesmas como o marco de referência da relação.

A inda a respeito da relação escola-família, há um outro aspecto que gostaríamos de destacar. Embora muitos educadores atribuam a origem dos problemas de indisciplina e violência ao ambiente familiar, nem sempre percebem a profunda interação entre as lógicas formativas exercidas nestes dois contextos, capaz de realimentar e tornar persistente os problemas que em tese se desejam resolver.

Finalmente, é preciso destacar a importância de que as diretrizes do enfrentamento de indisciplina e violência estejam em sintonia com 0 projeto pedagógico da escola, e que os procedimentos adotados assumam a natureza de atos efetivamente formativos. A conjugação proposta, entretanto, não parece surgir com facilidade nas escolas. Está em jogo a capacidade da escola manter uma reflexão sobre aquilo que fundamenta suas ações diante de indisciplina e violência. Assim, o projeto pedagógico precisa refletiro amadurecimento que a escola experimenta ao se defrontar com questões de indisciplina e violência, ao mesmo tempo em que as ações empreendidas devem refletir a visão pedagógica que a escola está propondo em seu projeto, onde explicita o que entende por educar.

Rev. Diálogo Educ., Curitiba, v. 9, n. 28, p. 511-523, set./ dez. 2009 


\section{CONCLUSÕES}

Nesta seção final do trabalho, reunimos algumas análises breves que reafirmam alguns argumentos desenvolvidos ao longo do texto. Mas não buscamos apresentar um quadro que sintetize todos os argumentos considerados anteriormente. Exercitamos aqui algumas escolhas, destacando apenas alguns pontos, que nos parecem particularmente fundamentais dentro do horizonte das questões exploradas.

Os desafios representados pelos eventos de indisciplina e violências nas escolas apresentam diversas implicações. Aqui argumentamos que, além de representar tensões, tais desafios nos mostram que é preciso pensar diferente para conceber práticas pedagógicas distintas daqueles em curso nas escolas. A lém disso, sugerem que precisamos conhecer em maior profundidade a dinâmica desses problemas, e sobretudo revisar e reconsiderar o próprio modo como temos concebido e interagido com eles no contexto escolar. Precisamos aprender com tais problemas a encontrar ações mais efetivas, pois eles têm algo a dizer sobre 0 ambiente escolar e sobre a própria necessidade de avanço pedagógico e institucional. Mas é preciso destacar que o que nos parece estar ao centro dessa discussão éa necessidade de repensarmos as próprias racionalidades que têm atravessado as perspectivas teóricas e as práticas relacionadas ao enfrentamento desses problemas nas escolas. Se indisciplina e violência representam uma crise na escola, essa crise também reflete as racionalidades que ali habitam. Nesse sentido, afirmamos que tais problemas refletem uma crise de paradigma, e portanto solicitam avanços tendo em mente essa perspectiva de mudança.

Neste artigo analisamos um conjunto dequestões sob a perspectiva de que para exercer novas formas de enfrentamento dos problemas de indisciplina e violência, devemos rever profundamente nossas perspectivas de gestão educacional. De fato, argumentamos pela necessidade de uma mudança de paradigma. Assim, exploramos a importância de exercer um enfrentamento daqueles problemas segundo uma perspectiva de gestão educacional que seja capaz de ampliar não somente o quadro dos recursos práticos a favor dos educadores, mas sobretudo de transformar culturas institucionais, de enfoques que pressupõe ações em decorrência daindisciplina e violência, rumo a enfoques onde as ações de desenvolvem sobretudo em precedência à possibilidade daqueles problemas.

Rev. Diálogo Educ., Curitiba, v. 9, n. 28, p. 511-523, set./ dez. 2009 
Ao longo do texto, argumentamos por enfoques pró-ativos tendo em mente superar as formas assimétricas como as escolas distribuem as ações e responsabilidades relativas aos encaminhamentos pedagógicos necessários, resultando comumente na ênfase de ações de intervenção. Além disso, sugerimos que seria fundamental avançarmos em direção a leituras sobre indisciplina e violência que superem visões e estratégias baseadas em simples controle social, que tanto esvaziam as relações pedagógicas. Nos parece mais produtivo pensar os desafios representados por indisciplina e violência como oportunidades para uma profunda revisão em nossas visões e práticas pedagógicas. Particularmente em termos de gestão educacional, seria oportuno avançar em direção a um outro paradigma.

\section{REFERÊNCIAS}

ABRAMOVAY, M.; RUA, A. Violências nas escolas. 4. ed. Brasília: Unesco, 2004. AMAD O, J. Interacção pedagógica e indisciplina na aula. Porto: Edições ASA, 2001.

AQUINO, J. (O rg.). Indisciplina na escola. São Paulo: Summus, 1996.

ARUM, R. Judging school discipline. Cambridge: Harvard University Press, 2005.

D 'ANTO LA, A. (Org.). Disciplina na escola. São Paulo: EPU, 1989.

DEBARBIEUX, E. Violência nas escolas. Lisboa: Instituto Piaget, 2007.

DEBARBIEUX, E.; BLAYA, C. (Org.). Violência nas escolas: dez abordagens européias. Brasília: Unesco, 2002.

ESTRELA, M. T. Relação pedagógica, disciplina e indisciplina na aula. Porto: Porto Editora, 2002.

FRELLER, C. H istónias de indisciplina escolar. São Paulo: Casa do Psicólogo, 2001.

FURLAN, A. D iscipline problems in the Mexican school system: the silence of educational science. Prospects, Brussels, v. 28, n. 4, p. 555-569, 1998.

GORD ON, D. Rising to the discipline challenge. Harvard Education Letter, Cambridge, v. 15, n. 5, p. 1-4, 1999.

Rev. Diálogo Educ., Curitiba, v. 9, n. 28, p. 511-523, set./ dez. 2009 
KUHN, T. A estrutura das revoluções científicas. São Paulo: Perspectiva, 1977. NÓVOA, A. Nota de apresentação. In: NÓVOA, A. (O rg.). Os professores e a sua formação. 2. ed. Lisboa: D om Quixote, 1995. p. 9-12.

REBELO, R. Indisciplina escolar: causas e sujeitos. Petrópolis: Vozes, 2002.

XAVIER, M. L. (O rg.). D isciplina na escola: enfrentamentos e reflexões. Porto Alegre: Mediação, 2002.

Recebido: 10/ 02/ 2009

Received: 02/ 10/ 2009

Aprovado: 15/ 03/ 2009

A pproved: 03/ 15/ 2009

Revisado: 16/ 09/ 2009

Reviewed: 09/ 16/ 2009

Rev. Diálogo Educ., Curitiba, v. 9, n. 28, p. 511-523, set./ dez. 2009 